doi: $10.47072 /$ demiryolu.944161

Issue:15, Page: $145-157$

http://dergipark.org.tr/demiryolu

e-ISSN: 2687-2463, ISSN: 2149-1607

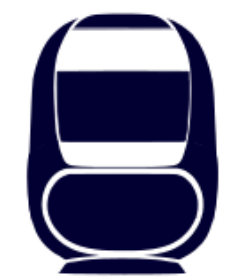

\title{
Orta Koridor Rotasında Türkiye'nin Liman bağlantılarının Bulanık AHP ve TOPSIS Yöntemleriyle Araştırılması
}

\author{
Ömer SACAR ${ }^{* 1} \oplus$, Sezgin ÖZDEMIR ${ }^{2} \oplus$ \\ ${ }^{1}$ Ergin Ăgaç Mesleki ve Teknik Anadolu Lisesi, Millî Ĕgitim Bakanlı̆̆g, Ulaştırma Hizmetleri, \\ Osmangazi, Bursa, Türkiye \\ ${ }^{2}$ TCDD Taşımacılık A.Ş. Genel Müdürlüğ̈̈ Ankara, Türkiye \\ *omersacar@hotmail.com
}

(Alınış/Received: 28.05.2021, Kabul/Accepted: 09.12.2021, Yayımlama/Published: 31.01.2022)

\begin{abstract}
Öz: Türkiye, jeopolitik konumu ile bölgesel ulaştırma koridorlarının merkezinde yer almaktadır. Çin'den başlayan Orta Asya'yı takiben Kazakistan ve Türkmenistan yoluyla Hazar Denizi'ni aşarak Kafkaslara ve Türkiye'ye gelen orta koridor çok önemli taşıma güzergâhıdır. Çin'in son yıllarda başlattı̆̆ Modern İpek Yolu güzergâhlarından birisi olan orta koridor, bilhassa denize sınırı olmayan ülkelerin ilgisini çekmektedir. Türkiye, tarihi İpek Yolu'nun yeniden canlandırılmasına yönelik olarak çeşitli projeler geliştirmektedir. Türkiye'nin büyük hacimli yükleri orta koridora çekmesi için demir yolu ve liman ilişkisinin kurması elzemdir. Bu çalışmada liman seçim problemlerinde paydaşlar için önemli kriterler araştırılmış, limanların teknik ve ticari özellikleri belirlenmiştir. Orta koridor üzerinden Türkiye' ye gelen ve deniz yolu ile devam edecek bir yük taşımasına en ideal liman seçimi Bulanık Analitik Hiyerarşi Süreci ve TOPSIS yöntemlerinin entegre edilmesiyle belirlenmiştir.
\end{abstract}

Anahtar kelimeler: Orta Koridor, İpek Yolu, Rota Optimizasyon, Bulanık AHP, TOPSIS

\section{Investigation of Turkey's port connections on the Middle Corridor Route with Fuzzy AHP and TOPSIS Methods}

\begin{abstract}
Turkey is located at the center of regional transportation corridors with its geopolitical location. The Middle Corridor, which starts from China, passes the Caspian Sea via Kazakhstan and Turkmenistan following Central Asia, and reaches the Caucasus and Turkey, is a very important transportation route. The Middle Corridor, one of the Modern Silk Road routes that China has started in recent years, attracts the attention of countries that do not have sea borders. Turkey develops various projects for the revitalization of the historical Silk Road. It is essential for Turkey to establish a railway and port connection in order to transport large volumes of cargo to the Middle Corridor. In this study, important criteria for stakeholders in port selection problems were investigated and the technical and commercial characteristics of the ports were determined. The most ideal port selection for a cargo transport that comes to Turkey via the middle corridor and will continue by sea is determined by integrating the Fuzzy Analytical Hierarchy Process and TOPSIS methods.
\end{abstract}

Keywords: Middle Corridor, Silk Road, Route Optimization, Fuzzy AHP, TOPSIS.

\section{Giriş}

Orta koridor, Londra ve Çin arasında olan demir yolu ağına verilen isimdir. Güzergah üzerindeki ülkelerin kendi demir yolu ağlarını iyileştirerek birbirine entegre edilmesi üzerine kuruludur. Güney koridor, Süveyş Kanalı rotasını, Kuzey koridor ise Rusya üzerinden Avrupa ile Çin'i bağlayan demir yolu hattını ifade etmektedir. Her sene Çin'den Avrupa'ya milyonlarca konteynerin Güney koridor ile gönderilmesi, taşımacılıktaki hacmin büyüklüğünü göstermektedir. Bir y1l içinde Çin'den Avrupa'ya giden 10 milyon konteynerin yüzde 96's1 denizyoluyla, yüzde 4'ü kuzey koridorundan sevk ediliyor. Diğer güzergâhlara alternatif olan orta koridor, kuzey koridoruna oranla daha hızlı, 2 bin km daha kısa, iklim koşulları bakımından da 
daha elverişlidir. Deniz yolu ile gidilen güney koridoruna kıyasla ulaşım süresini üçte bir oranında (15 gün) kısaltmaktadır. Orta koridor sadece doğu batı eksenli ulaşım sunmamakta Türkiye'nin liman bağlantıları ile Asya'daki yük trafiğinin Orta Doğu, Kuzey Afrika ve Akdeniz bölgesine ulaştırmayı mümkün kılmaktadır. Türkiye'nin son zamanlarda gerçekleştirdiği, Kuzey Marmara Otoyolu, Çanakkale Köprü Projesi, Marmaray, yüksek hızlı tren hatları, limanların genişletilmesi gibi büyük yatırımlar sadece kendisi için değil, uzun vadede orta koridora lojistik alt yapı olarak analiz edilmektedir. Türkiye orta koridorda Yunanistan ile rakip sayılabilmektedir. Çin'in yatırım yaptığı Pire Limanı güney koridorunda güzergâhın bittiği yer olup Port Said'den 580 deniz mili mesafededir. Pire Limanı'na inen yük $A B$ topraklarına doğrudan girmekte ve demir yolu bağlantılarıyla $\mathrm{AB}$ içlerine kolaylıkla eriştirilebilmektedir. Türk limanlarının Avrupa Birliği güzergâhında Marmara Denizi öne çıkmaktadır. Marmara Denizinde herhangi bir limana giden ana gemi, yaklaşık 750 deniz mili mesafe kat ederek, akabinde besleme hatlarla Karadeniz limanlarına ya da kara yoluyla Orta ve Doğu Avrupa'ya aktarma yapılabilmektedir. Bu noktada Türkiye sadece Uzakdoğu - Avrupa ana deniz ticaret rotasının değil, Karadeniz - Akdeniz deniz ticaret rotasının da merkezinde yer almaktadır [1].

Türkiye'nin bölgesel ticaret üssü olabilmesi; Akdeniz ve Karadeniz pazarlarında rekabet edebilmesine bağlıdır. Doğu-batı eksenli alınan yüklerin, kuzey-güney istikametli yönlendirilebilmesi, yük türlerinde uzmanlaşmak ve konteyner taşımacılığına yönelik yeni limanların oluşturulması ile mümkün olacaktır. $\mathrm{Bu}$ sebeple Türkiye bölgesel ticaret üssü olabilmek ve taşımacılıkta öne çıkabilmek için yeni liman yatırımları yapmaktadır.

Tüm bu hedefler ve yeni yatırımlar doğrultusunda orta koridor ve Türkiye limanlarının bağlantısının araştırılması, en uygun liman seçimi uygulaması literatürde boşluk olarak görülmüş ve çalışmada bu amaca yönelik optimal sonuç veren yöntemler kullanılmıştır. Orta koridor üzerinden Türkiye' ye gelen ve deniz yolu ile devam edecek bir yük taşıması için en uygun liman seçimi amacıyla öncelikle paydaşlar için önemli kriterler araştııılmış, limanların teknik ve ticari özellikleri belirlenmiştir. Sonrasında ise belirlenen kriterlerin ağırlıklandırılması bulanık analitik hiyerarşi süreci yöntemiyle hesaplanmıştır. Limanların seçiminde dikkate alınacak nihai sıralamaya ise TOPSIS yönteminin uygulanmasıyla ulaşı1mıştır.

\section{Limanlar}

Limanlar bir ülkenin dünyaya açılan kapısıdır. Limanlar ile ülkeler dünya ticaretinde öne çıkabilmektedir. Dünya tarihinde önemli bir medeniyet yoktur ki, denizler ile bütünleşmiş olmasın. Türkiye'de yüzlerce yıldır denizler ile çevrili, ticaret yollarının kesiştiği bir çevrede yer almaktadır. Türkiye'yi bölgesel anlamda öne çıkartan en önemli unsurlardan birisi denizlere sahip olmasıdır. Buna bağlı olarak deniz yolu taşımacılığına için oldukça elverişli olan Türkiye'nin uluslararası pazarlara ulaşmasında limanlar önemli rol oynamaktadır.

Küreselleşme ile birlikte limanlar sadece bölgesel yüke hizmet veren limanlar olmaktan çıkmış ve bir bölgenin limanı olmaktan çok bölgedeki yük trafiğinin limanı olma yönünde gelişme göstermiştir. Limanlar yapılanmalarını bölgelerindeki aktarma yüklerinden daha fazla pay almak için düzenlemektedir. Türkiye limanları, Doğu Akdeniz ve Karadeniz denizcilik hatlarında stratejik konumda yer almakta ve Doğu-Batı ve Kuzey-Güney yönlü uluslararası ulaştırma koridorlarının kesişim noktasında bulunmaktadır. Bulundukları avantajlı konum ile aktarma/transit yükleri çekebilecek özelliktedirler.

Türkiye'nin her bir bölgesinde bulunan limanları farklı ulaştırma ağlarına hizmet verebilecek konumda yer almaktadır. Akdeniz ve Ege Bölgesi'ndeki limanlar, kısa sapma mesafeleri ile Akdeniz'den geçen Asya-Avrupa ana denizcilik hattının yüklerini çekebilecek konumda yer almaktadır. Türkiye'nin Orta Doğu ve Asya ülkelerine ana denizcilik hattından gelen yüklerin iletilmesinde aktarma/transit limanı olarak Akdeniz limanları öne çıkmaktadır. Marmara 
limanları; Avrupa Birliği tarafindan oluşturulan Trans-Avrupa ve Pan-Avrupa ulaştırma koridorlarının Türkiye bağlantısı ve bu koridorların Doğu'ya uzatılması açısından öne çıkmaktadır. Marmara limanları ile Pan-Avrupa 4. koridoru ile Avrupa ülkelerinden Marmara limanlarına gelen yüklerin karayolu, demir yolu veya denizyoluyla Doğu ülkelerine transferi yapılabilecektir. Orta Asya ülkelerinin Avrupa ile ticaretinde en önemli ulaşım alanı olarak Karadeniz'deki limanlar düşünülebilmektedir.

Kuzey-Güney ulaştırma koridoru ile İran ve Hindistan'a kadar ulaşan Avrupa merkezli yükler Türkiye'den geçebilmektedir. Türkiye'deki limanların tercih edilmesinin tek nedeni coğrafi konum değil, liman operasyonlarının verimliliği, hizmet kalitesi, uygun liman ve bölgenin ulaşım altyapısıdır. Limanlar ancak hizmet sunduğu art alana ulaşımında karayolu ve demir yolu bağlantıları oranında öne çıkmaktadır. Türkiye'de bazı limanların demir yolu bağlantısının olmayışı en önemli altyapı eksikliği olarak ortaya çıkmaktadır. Özellikle konteyner trafiğinde \% 90 paya sahip olan özel limanların demir yolu bağlantılarının bulunmaması, kombine taşımacılığın maliyet avantajlarından yararlanılamamasına yol açmaktadır. Konteyner taşımacılığı, demir yolu ile deniz yolunun entegre edilmesi ile anlamlı olacaktır. Bu sebeple demir yolu taşımacılığı konteynerin deniz dışındaki ulaşımı için en ideal ulaştırma modlarından birisidir.

Limanların seçiminde yüklerin daha ekonomik, hızlı ve güvenli şekilde aktarılması, liman ücretleri gibi bir takım faktörler öne çıkmaktadır. Bunlar ile beraber limanın ana denizcilik hatlarına yakın olması, kombine taşımacılık için gerekli alt yapıya sahip olması ana güzergâhtan sapma mesafelerinin kısa olması önemli hususlar arasındadır. Limanın altyapı ve üstyap1 imkânlarının gelişmiş olması, liman hizmetlerinin müşteri gereksinimleri doğrultusunda şekillenmesi ve katma değerli hizmetler sunulması, operasyonel açıdan verimlilik, liman kalitesini etkileyen faktörler arasındadır. Tüm bu etmenler, firmaları liman seçiminde etkilemektedir.

\section{Literatür Araştırması}

Literatürde Modern İpekyolu ile ilgili birçok çalışma mevcut olmakla beraber bu alanda yapılan çalışmalar özellikle liman yeri seçim problemlerinden oluşmaktadır. Çalışmaların birçoğunda lojistik, gemi ve liman işletme firmaları için önem arz eden kriterler kullanılarak çözüme ulaşılmıştır. Bu kısımda literatürde yapılan çalışmalar ve makale kapsamındaki uygulamanın getirdiği yenilikler açıklanmıştır.

Karataş ve Oral Limanların aktarma yüklerinden aldıkları payı artırabilmeleri amaçlanarak aktarma limanı seçim kriterlerinin tespit edilmiş ve Türkiye limanlarının belirlenen kriterlerdeki etkinliği büyük ölçüde sağladıkları belirtilmiştir [2]. Akbayırlı vd. gelişen hinterlant bağlantıları, liman inovasyonları, liman özelleştirme politikaları ve liman kullanıcılarının değiş̧en özel beklentileri doğrultusunda rekabete açık hinterlantlardaki liman kullanıcılarının liman seçim kriterlerini araştırmak ve bu liman kullanıcılarının seçim kriterlerini ölçen ve 32 kriterden oluşan bir model geliştirmişlerdir [3]. Pekkaya ve Bucak Türkiye-Batı Karadeniz Bölgesi'ndeki alternatif 4 liman yeri arasından liman kuruluş yeri seçimini etkileyen kriterlerin önem derecelerini belirlemek amaciyla PROMETHEE, TOPSIS, ÇKPM, VIKOR yöntemlerini karşılaştırarak liman kuruluş yeri seçimi için PROMETHEE yönteminin uygulanabilirliğini araştırmışlardır [4]. Aydın vd. liman yer seçimi probleminde etki eden ekonomik, çevresel ve sosyo-kültürel unsurları göz önünde bulundurarak Antalya ilinde kruvaziyer liman yer seçimi uygulaması yapmışlardır [5]. Özyağcı ve Oral kara terminali olarak adlandırılan (Dryport) tesislerin temel fonksiyonları incelenerek; çok modlu (multimodal) taşımacılık temelinde en uygun kara terminal yeri seçiminde CBS kullanımı Odessa Bölgesi limanları için örnek bir çalışma olarak verilmiştir [6]. Zeybek, demiryollarının konteyner limanlarının hinterlant bağlantılarındaki önemi incelenmiş, liman hinterlandında demiryolu taşımacılığının gelişmesine yönelik güçlü ve zayıf yönler ile fırsat ve tehditleri tespit etmek amacıyla Mersin Limanı örnek 
alınarak bir SWOT analizi yapılmıştır [7]. Zeybek, Çin'den başlayıp Türkiye'den geçerek Avrupa'ya ulaşan Orta Koridor'a odaklanarak kıtalar arası demiryolu konteyner taşımacılığının gelişmesine yönelik firsat ve tehditleri PESTLE analizi ile ortaya koymak, ayrıca Kuşak ve Yol Girişimi(BRI)'nin kıtalar arası demiryolu konteyner taşımacılığına etkisini incelemektir [8]. Özel konteyner liman yerinin seçiminde maliyet, sürdürülebilirlik, performans ve fizki koşullar kriterleri altında çok kriterli karar verme çözümlerinden VIKOR yöntemini uygulamıştır [9]. Murphy vd. liman seçim faktörlerine etki eden kirteleri yerel taşımacılar, uluslararası gemi işletmecileri, uluslararası liman işletmecileri ve uluslararası lojistik firmaları gibi çeşitli katılımcıların beklentilerini dikkate alarak ortaya koymuştur [10]. Malchow ve Kanafani ABD'de limanlar arasındaki bağlantıların değerlendirilmesinde coğrafi konum, liman özellikleri ve gemi programları kriterlerini kullanarak her bir yük türü ve taşıyıcı firma için seçim sürecine etkilerini açıklamışlardır [11]. Murphy ve Daley uluslararası nakliyatçılar ve liman işletmecilerinin bakış açılarını analiz etmek amacıyla liman seçim faktörlerinin karşılaştırmalı analizlerini yapmışlardır [12]. Slack, Kuzey Amerika Orta Batı ve Batı Avrupa arasındaki konteyner trafiğine odaklanılarak, ihracatçılar ve nakliye firmaları tarafından dikkate alınan faktörler ışığında akliyatçıların liman seçimi sürecinde kullandıkları kriterleri araştırmaktadır [13] . Lirn vd. küresel okyanus konteyneri operatörlerini kapsayan 12 kriter kullanarak 20 liman arasında aktarma limanı seçiminde AHP uygulamasını kullanmıştır [14]. Alonso ve Soriano liman seçim kriterlerin belirlenmesinde etkili olan karar verici grupların homojen dağılmadığını savunarak bu kriterlerin etkinliğini arttırmak için hinterland perspektifini ve ayrık seçim modelleme yaklaşımını kullanmışlardır [15]. Lirn vd aktarma limanı seçimi karar verme sürecinde çeşitli kriterlerin önemini belirlemek için bulanık AHP tekniğini kullanmışlardır [16]. Lam, müşterilerin ve lojistik firmalarının beklentilerinden yola çıkarak bağlantı noktası seçimi ile ilgili literatürü özetlemiş, AHP metodolojisi kullanılarak bağlantı noktası seçimi için bir karar destek sistemi önermiştir [17]. Feng vd. 21. Yüzyıl Deniz İpek Yolu boyunca üye ülkeler arasında liman işbirliğininin etkinliklerini tanımlamış ve bunlar arasında oyun teorisine dayalı yol seçim problemine çözüm getirmiştir [18]. Song vd, Bayes ağlarının geçerliliğini ve avantajlarını ayrıntılı olarak kanıtlamak için 21. yüzyıl Deniz İpek Yolu" nun optimum liman yatırımı karar verme problemi ile ilgili bir vaka örneği sunulmuştur [19]. Gao vd, Fuzzy-AHP ve ELECTRE III modeline dayalı çin'deki Quanzhou Limanı'nın kuşak ve yol üzerindeki rekabet edebilirliğinin incelemişlerdir [20]. Chou, Uluslararası ticaret konteyner taşımacılığı işletme maliyetini düşürmek ve liman aktarma hizmetlerindeki etkinliği arttırılması için konteyner liman seçim probleminde bulanık çok kriterli karar verme yöntemi uygulamıştır [21]. Tran, gemi maliyeti, liman tarifesi, iç nakliye maliyeti ve envanter maliyeti dahil olmak üzere toplam maliyeti en aza indirme amaçlı liman seçim probleminde iman seçimi kararında lojistik faktörlerin etkisini analiz etmiştir [22]. Bagocius vd, Ekonomik ihtiyaçları karşılamak için Klaipeda bölgesinde bir derin deniz limanı yer seçimi için entropi ve WASPAS yöntemlerinin bir kombinasyonu kullanmışlardır [23]. Onwuegbuchunam, Nijeryada kıyı limanlarında mevcut olan yolcu gemisi hizmetlerini kullanan Nijeryalı nakliyatçıların liman seçim kriterlerini ampirik olarak araştırmış, vinç verimliliğinin, yani limandaki yük elleçleme hızının, liman tesislerinin seviyesi ve işlevselliğinin, sevkiyat boyutunun, Gemi çağırma sıklığı ve limana olan antrepo mesafesi, petrol dışı deniz taşımacılığı yapan göndericilerin, sevkiyat yapmak için limanları seçerken dikkate aldıkları en önemli faktör olduğu sonucuna varmıştır [24]. Zavadskas vd, Baltık Denizinin Doğu ve Batı Avrupa arasında bir arteriyel ulaşım koridorundaki coğrafik önemine değinerek bu bölgede yapılacak bir liman için yer seçimi probleminin çözümünde Analitik Hiyerarşi (AHP) ve Bulanık Oran Değerlendirme (ARAS-F) yöntemlerini kombine etmiştir [25].

Literatürdeki çalışmalara bakıldığında, birçoğunu liman yeri seçim problemlerinin oluşturduğu görülmektedir. Lojistik faaliyetler temel olarak altyapı ve işletme olarak iki ana kola ayrılmaktadır. Literatürdeki örneklerin birçoğunu altyapı olarak tanımlanan liman inşası için yer seçimine ait çalışmalar oluşturmaktadır. Bu makale kapsamında yapılan çalışma ise kombine bir yük taşıması için en ideal liman seçimi problemi ele alınmıştır. Daha önce kullanılan çok kriterli karar verme problemleri çalışma kapsamındaki uygulamada orta koridor üzerinden Türkiye' ye 
gelen ve denizyolu ile devam edecek bir yük taşıması için optimal liman seçimine yeni bir yaklaşım getirmiştir.

\section{Kullanılan Metot}

Karar verme problemlerinde birden fazla kriter ve alternatif olduğu durumlarda en ideal çözüme ulaşmada çok kriterli karar verme yöntemleri uygulanmaktadır. Karar vericilerin belirlediği kriter önemleri ve alternatiflerin gerçek değerlerinin bir arada kullanılmasıyla çok kriterli karar verme yöntemleri optimal sonuçlar vermektedir. $\mathrm{Bu}$ uygulamada çok kriterli karar verme yöntemlerinden bulanık analitik hiyerarşi süreci ve TOPSIS yöntemi bir arada kullanılmıştır. Liman seçim problemlerinde paydaşlar için önem arz eden kriterler ve limanların teknik ve ticari özellikleri belirlenmiş ve bu iki yöntem bir arada kullanılarak orta koridor üzerinde Türkiye' ye gelen ve deniz yolu ile devam edecek bir yük taşıması için en ideal liman seçimi için bir yöntem önerilmiştir.

$\mathrm{Bu}$ kısımda uygulamanın çözümü aşamasında kullanılan bulanık analitik hiyerarşi süreci ve TOPSIS yöntemlerinin notasyonları verilmiştir.

\subsection{Bulanık analitik hiyerarşi süreci}

Çok kriterli karar verme yöntemlerinin en sık kullanılanlarından bir tanesi analitik hiyerarşi sürecidir. Fakat belirsizliğin arttığı, sayısal değerlerin yeterli kalmadığı durumlarda bulanık mantık devreye girmekte, problemlerin çözümünde bu yöntemlerin kullanılması büyük kolaylık sağlamaktadır. Tüm hizmet sektörlerinde olduğu gibi lojistik sektöründe de karar verme sadece sayısal veriler yeterli olmayıp kalitenin ölçülmesinde kullanılan ve dilsel değerlerle ifade edilen ağırlıklar bulunmaktadır. Böyle durumlarda bulanık analitik hiyerarşi prosesinin kullanılması karar vericilere büyük kolaylık sağlamaktadır. Literatürde birçok bulanık AHS kullanılmasına rağmen bunların arasında hesaplama yöntemi ve puanlandırma kolaylığı sağlayan ve ilk olarak Chang tarafindan ortaya çıkarılan genişletilmiş bulanık AHS yöntemidir. Yöntemin temel çalışma adımları aşağıdaki gibidir [26].

1.Adım: Bulanık yapay büyüklük değeri, i. nesneye göre söyle tanımlanır:

$$
s_{i}=\sum_{j=1}^{m} M_{g_{i}}^{j} *\left[\sum_{i=1}^{n} \sum_{j=1}^{m} M_{g i}^{j}\right]^{-1}
$$

$\sum_{j=1}^{m} M_{g i}^{j}$ ifadesini elde etmek için m değerleri üzerinde bulanık sayılarda toplama işlemini aşağıdaki şekilde elde edilir.

$$
\sum_{j=1}^{m} M_{g i}^{j}=\left(\sum_{j=1}^{m} l_{i}, \sum_{j=1}^{m} m_{i}, \sum_{j=1}^{m} u_{i}\right)
$$

$\left[\sum_{i=1}^{n} \sum_{j=1}^{m} M_{g i}^{j}\right]^{-1}$ ifadesini elde etmek için $M_{g i}^{j}(\mathrm{j}=1,2,3, \ldots, \mathrm{m})$ üzerinde bulanık toplama işlemi yapılır. 


$$
\sum_{i=1}^{n} \sum_{j=1}^{m}=\left(\sum_{i=1}^{n} l_{i}, \sum_{i=1}^{n} m_{i}, \sum_{i=1}^{n} u_{i}\right)
$$

Son olarak ise Eşitlik 1'deki denklemin vektörün tersi hesaplanır.

$$
\left[\sum_{i=1}^{n} \sum_{j=1}^{m} M_{g i}^{j}\right]^{-1}=\left(\frac{1}{\sum_{i=1}^{n} u_{i}}, \frac{1}{\sum_{i=1}^{n} m_{i}}, \frac{1}{\sum_{i=1}^{n} l_{i}}\right)
$$

2.Adım: $M_{1}=\left(l_{1}, m_{1}, u_{1}\right) \leq M_{2}=\left(l_{2}, m_{2}, u_{2}\right)$ ifadesinin olasılık derecesi aşağıdaki şekilde tanımlanır.

$$
V\left(M_{2} \geq M_{1}\right) \sup _{y \geq x}\left[\min \left(\mu_{M 1}(x), \mu_{M 2}(y)\right)\right]
$$

$M_{1}=\left(l_{1}, m_{1}, u_{1}\right) \quad$ ve $M_{2}=\left(l_{2}, m_{2}, u_{2}\right)$ üçgensel bulanık sayılar olmak üzere;

$V\left(M_{2} \geq M_{1}\right)=\operatorname{hgt}\left(M_{1} \cap M_{2}\right)=\mu_{M 2}(d)=\left\{\begin{array}{rc}1, & m_{2} \geq m_{1} \\ 0, & l_{1} \geq u_{2} \\ \frac{l_{1}-u_{2}}{\left(m_{2}-u_{2}\right)-\left(m_{1}-l_{1}\right)}, & \text { diğer durumlarda }\end{array}\right.$

İfadesi elde edilir.

3.Adım: Konveks bir bulanık sayının olasılık derecesinin k konveks sayıdan $M_{i} \quad(\mathrm{i}=1,2, \ldots, \mathrm{k})$ daha büyük olması aşağıdaki şekilde tanımlanabilir.

$$
\begin{aligned}
V\left(M \geq M_{1}, M_{2}, M_{3} \ldots, M_{k}\right) & =V\left[\left(M \geq M_{1}\right),\left(M \geq M_{2}\right),\left(M \geq M_{k}\right)\right] \\
& =\operatorname{minV}\left(M \geq M_{i}\right) \quad i=1,2, \ldots, k
\end{aligned}
$$

$k=1,2, \ldots, n ; \quad \mathrm{k} \neq \mathrm{j} \quad$ için $d^{\prime}\left(A_{i}\right)=\min V\left(S_{i} \geq S_{k}\right.$ olarak alınırsa ağırlık vektörü aşağıdaki şekilde elde edilmiş olur.

$$
W^{\prime}=\left(d^{\prime}\left(A_{1}\right), d^{\prime}\left(A_{2}\right), \ldots, d^{\prime}\left(A_{n}\right)\right)^{T}
$$

Burada $A_{i}(i=1,2, \ldots, n)$ n elemandan oluşur.

4.Adım: Eşitlik 6' da verilen ağırlık vektörü normalize edildiğinde;

$$
W=\left(d\left(A_{1}\right), d\left(A_{2}\right), \ldots, d\left(A_{n}\right)\right)^{T}
$$

Vektörü bulunmuş olur ve bu $\mathrm{W}$ ağırlık vektörü bulanık bir sayı değildir.

Bulanık AHS yönteminde kriterlerin ağırlıklandırılmasında kullanılan önem ölçeği ise aşağıdaki gibidir [26]. 
Tablo 1. Bulanık AHS önem ölçeği

\begin{tabular}{lcc}
\hline \multicolumn{1}{c}{ Açıklama } & Önem Derecesi & Önem Derecesi Eşleniği \\
\hline Eşit Önemli & $(1,1,1)$ & $(1,1,1)$ \\
Daha Önemli & $(2 / 3,1,3 / 2)$ & $(2 / 3,1,3 / 2)$ \\
Çok Daha Önemli & $(3 / 2,5,5 / 2)$ & $(2 / 5,1 / 2,2 / 3)$ \\
Çok Fazla Önemli & $(5 / 2,3,7 / 2)$ & $(2 / 7,1 / 3,2 / 5)$ \\
Kesin Önemli & $(7 / 2,4,9 / 2)$ & $(2 / 9,1 / 4,2 / 7)$ \\
\hline
\end{tabular}

\subsection{TOPSIS yöntemi}

Hwang ve Yoon tarafindan 1981 yılında çok kriterli karar verme tekniği olarak geliştirilen TOPSIS yöntemi, çözüm alternatifinin pozitif-ideal çözüme en kısa mesafe ve negatif-ideal çözüme en uzak mesafeyi hesaplayabilme amacına göre oluşturulmuştur. TOPSIS yöntemi ile az sayıda veri kullanılarak anlaşılır bir sonuç elde edilebilmektedir. İdeal çözüme yakınlık karın maksimizasyonu, negatif ideal çözüme uzaklık ise maliyetin minimizasyonu anlamına gelmektedir. Ulaşılmak istenilen hedefin ideal çözüme yakın olması istenilirken aynı zamanda negatif ideal çözümden uzak olması beklenir. TOPSIS yöntemi adımları aşağıdaki şekilde siralanır [27].

1. Karar matrisinin oluşturulması,

2. Normalize matrisin elde edilmesi,

3. Ağırlıklandırılmış normalize matrisin elde edilmesi,

4. İdeal ve negatif ideal çözüm değerlerinin elde edilmesi,

5. İdeal ve negatif ideal noktalara olan uzaklık değerlerinin elde edilmesi,

6. İdeal çözüme göreli yakınlığın hesaplanması.

\section{Uygulama}

Uygulama Türkiye'ye orta koridor üzerinden gelen ve diğer ülkelere deniz yolu ile devam edecek bir yük taşıması için en ideal liman seçimi önerisi yapılmıştır. Öncelikle Türkiye'de demiryolu bağlantılı limanlar alternatif olarak belirlenmiş, sektör paydaşlarının taşımalar için önem arz eden kriterleri altında belirlenen limanlar bulanık AHS ve TOPSIS yöntemleri kullanılarak değerlendirilmiştir.

\subsection{Alternatiflerin belirlenmesi}

Uygulamada alternatif olarak Türkiye'de demiryolu bağlantılı limanlar alternatif olarak belirlenmiş, limanlara ait özelliklere bu kısımda yer verilmiştir.

Haydarpaşa Limanı: Haydarpaşa Limanı 20.04.1899 tarihinde Anadolu Bağdat Demiryolları Kumpanyasına inşa ettirilmeye başlanmış ve 1924 senesine kadar bu kumpanya tarafindan işletilmiştir. Daha sonra TCDD işletmesine devredilmiş olup gerçek anlamda 1967 yılında hizmete girmiştir [28].

İzmir Limanı: Yapımına 1957 yılında başlanmış olup 1964 yılından itibaren 440 sayılı Kanun çerçevesine alınan Denizcilik Bankası TAO İktisadi Devlet Teşekkülü olarak faaliyetine devam etmiştir. Yüksek Planlama Kurulu'nun 16.12.1988 tarih ve 88/121 sayılı Kararı ile İzmir Liman İşletmesi; 1 Ocak 1989 tarihi itibariyle TCDD’ye devredilmiştir [28]. 
Bandırma Limanı: Mazisi M.Ö. 8-10. Yıllara kadar uzanan liman ciddi anlamda 1924 yılında inşa edilen Belediye İskelesi ile faaliyete geçmiştir. Bugünkü modern limanın temelleri ilgili çalışmalar etüt ve proje bazında 1952 yılında başlatılmış, inşasına ise 1963 senesinde başlanmıştır. 2004 yılında yapılan ihale sonucunda Çelebi Ortak Girişim Grubuna, 18.05.2010 tarihinde 36 yıl süreyle işletilmek üzere devredilmiş̧ir. Liman, faaliyetlerine Çelebi Bandırma Uluslararası Liman İşletmeciliği A.Ş. adı altında devam etmektedir [29].

Derince Limanı: Liman 1900 yılında verilen bir imtiyazla Anadolu Bağdat Demiryolları Kumpanyası tarafından inşaatına başlanılıp, 1904 yılında işletmeye açılmıştır. 2004 yılında Safi Katı Yakıt Sanayi ve Ticaret A.Ş. 39 yıl süreyle işletilmek üzere devredilmiştir. Liman, faaliyetlerine Safi Derince Uluslararası Liman İşletmeciliği A.Ş. adı altında devam etmektedir [30].

İskenderun Limanı: İsminden de anlaşılacağı üzere mazisi (M.Ö. 333) Büyük İskender'e dayanan bölgede 1909 yılında Anadolu - Bağdat Demiryolları Kumpanyasına verilen Limanın inşa imtiyazı sonralı Kanunla Devlet Demiryolları İdaresi'ne fiilen devredilmiş, 2004 yılında ise Limak Yatırım Enerji Üretim İşletme Hizmetleri ve İnşaat A.Ş,'ne 36 yıl süreyle işletilmek üzere devredilmiştir. Liman, faaliyetlerine Limak İskenderun Uluslararası Liman İşletmeciliği A.Ş. adı altında devam etmektedir [31].

Mersin Limanı: Mısır'da Süveyş Kanalının inşa edilmeye başlanması ile birlikte, Mersin bir liman olarak daha fazla önem kazanmaya başlamıştır. 1890 yıllarda doğal liman çerçevesinde taşımacılık faaliyetleri hız kazanmış, yeni iskeleler yapma ihtiyacı doğmuştur. 1942 yılında Devlet Demiryolları ve Limanları İşletme Umum Müdürlüğüne devredilmiştir. 2004 y1lında PSA Akfen Ortak Girişim Grubuna 36 yıl süreyle işletilmek üzere devredilmiştir. Liman, faaliyetlerine Mersin Uluslararası Liman İşletmeciliği A.Ş. (MIP) adı altında devam etmektedir [32].

Samsun Limanı: M.Ö. 3500 yıllarına dayanan şehrin yapılanması ile birlikte bu tarihten itibaren bugünkü Samsun Limanı tabii liman olarak kullanılmıştır. 1953 yılında TCDD’ye devredilmiştir. 2004 yılında Ceynak Lojistik ve Ticaret A.Ş.’ne 36 yıl süreyle işletilmek üzere devredilmiştir. Liman, faaliyetlerine Samsun Uluslararası Liman İşletmeciliği ( Samsunport) adı altında devam etmektedir [33].

\subsection{Kriterlerin belirlenmesi}

Kriterlerin belirlenmesi sektör paydaşlarının beklentileri ve günlük hayat verileri etkili oluş olup kriterlere ait açıklamaya bu kısımda yer verilmiştir.

Gemi Kabul Kapasitesi: Bir yıl içerisinde liman rıhtıma yanaşabilen gemi sayısı olarak ifade edilir.

Konteyner Elleçleme Kapasitesi: Limana gelen yüklerin bir yıllık periyotta özel elleçleme ekipmanları aracılığılla gemiden indirilmesi ve yüklenmesinin kapasitesidir.

Konteyner depolama kapasitesi: Limana gelen konteynerlerin lojistik faaliyet işlemleri tamamlanana kadar depolama kapasitedir.

Yükleme-Boşaltma ücreti: Konteynerlerin limana gelen gemilere yüklenmesi ve boşaltılması faaliyetleri için konteyner başına ödenen ücret olarak tanımlanır.

Ardiye ücreti: Limana indirilen konteynerlerin ücretsiz bekleme süresinden sonra gün başına ödenen ücret olarak tanımlanır. 


\subsection{Kriterlerin Bulanık AHS yöntemiyle ăğılıklandırılması}

$\mathrm{Bu}$ aşamada sektör paydaşlarınca belirlenen beş adet kriter Eşitlik $1-8$ yardımıyla ağırlıklandırılmış ve kriterlerin önem ağırlıkları elde edilmiştir.

Tablo 2. İkili karşılaştırma matrisinin oluşturulması

\begin{tabular}{|c|c|c|c|c|c|c|c|c|c|c|c|c|c|c|c|}
\hline Kriter Ad 1 & \multicolumn{3}{|c|}{$\begin{array}{c}\text { Gemi Kabul } \\
\text { Kapasitesi }\end{array}$} & \multicolumn{3}{|c|}{$\begin{array}{c}\text { Toplam } \\
\text { Elleçleme } \\
\text { Kapasitesi }\end{array}$} & \multicolumn{3}{|c|}{$\begin{array}{c}\text { Toplam } \\
\text { Stoklama } \\
\text { kapasitesi }\end{array}$} & \multicolumn{3}{|c|}{$\begin{array}{c}\text { Yükleme- } \\
\text { Boşaltma ücreti }\end{array}$} & \multicolumn{3}{|c|}{$\begin{array}{l}\text { Ardiye } \\
\text { ücreti }\end{array}$} \\
\hline $\begin{array}{l}\text { Gemi Kabul } \\
\text { Kapasitesi }\end{array}$ & 1 & 1 & 1 & 1 & $1 / 2$ & $1 / 3$ & $1 / 2$ & $1 / 3$ & $1 / 4$ & $1 / 2$ & $1 / 3$ & $1 / 2$ & 1 & $1 / 2$ & $1 / 3$ \\
\hline $\begin{array}{l}\text { Toplam } \\
\text { Elleçleme } \\
\text { Kapasitesi }\end{array}$ & 3 & 2 & 1 & 1 & 1 & 1 & 1 & 2 & 3 & 1 & $1 / 2$ & 1 & 1 & $1 / 2$ & $1 / 2$ \\
\hline $\begin{array}{l}\text { Toplam } \\
\text { Stoklama } \\
\text { kapasitesi }\end{array}$ & 2 & 3 & 2 & $1 / 3$ & $1 / 2$ & 1 & 1 & 1 & 1 & $1 / 2$ & $1 / 3$ & $1 / 2$ & 1 & 1 & 1 \\
\hline $\begin{array}{l}\text { Yükleme- } \\
\text { Boşaltma } \\
\text { ücreti }\end{array}$ & 2 & 3 & 2 & 2 & 1 & 2 & 2 & 3 & 2 & 1 & 1 & 1 & 2 & 1 & 2 \\
\hline $\begin{array}{l}\text { Ardiye } \\
\text { ücreti }\end{array}$ & 3 & 2 & 2 & 2 & 2 & 2 & 2 & 1 & 2 & $1 / 2$ & 1 & $1 / 2$ & 1 & 1 & 1 \\
\hline
\end{tabular}

Öncelikle tüm kriterlerin birbirleri arasındaki karşılaştırılmasının gösterildiği ikili karşılaştırma matrisi oluşturulmuştur ve Tablo 2' de verilmiştir.

Tablo 3. Bulanık karşılaştırma değerinin geometrik ortalaması

\begin{tabular}{lccc}
\hline Kriter Adı & \multicolumn{3}{c}{$\mathrm{ri}_{\mathrm{i}}$} \\
\hline Gemi Kabul Kapasitesi & 0,758 & 0,488 & 0,425 \\
Toplam Elleçleme Kapasitesi & 1,246 & 1,000 & 1,084 \\
Toplam Stoklama kapasitesi & 0,803 & 0,871 & 1,000 \\
Yükleme - Boşaltma ücreti & 1,741 & 1,552 & 1,741 \\
Ardiye ücreti & 1,431 & 1,320 & 1,320 \\
Toplam & 5,978 & 5,230 & 5,570 \\
Tersine Çevrilmiş & 0,167 & 0,191 & 0,180 \\
Artan Düzende & 0,167 & 0,180 & 0,191 \\
\hline
\end{tabular}

Tablo 4. Bulanık karşılaştırma değerinin geometrik ortalaması

\begin{tabular}{lccc}
\hline Kriter Adı & & $\mathrm{W}_{\mathrm{i}}$ & \\
\hline Gemi Kabul Kapasitesi & 0,127 & 0,088 & 0,081 \\
Toplam Elleçleme Kapasitesi & 0,208 & 0,180 & 0,207 \\
Toplam Stoklama kapasitesi & 0,134 & 0,156 & 0,191 \\
Yükleme - Boşaltma ücreti & 0,291 & 0,279 & 0,333 \\
Ardiye ücreti & 0,239 & 0,237 & 0,252 \\
\hline
\end{tabular}


Sonraki adımda ise bulanık karşılaştırma değerinin geometrik ortalaması $\left(\mathrm{w}_{\mathrm{i}}\right)$ hesaplanmış ve Tablo 4 yardımıyla gösterilmiştir.

Tablo 5. Kriterlerin ortalama ve normalleştirilmiş ağırlığ1

\begin{tabular}{lll}
\hline Kriter Adı & $\mathrm{M}_{\mathrm{i}}$ & $\mathrm{N}_{\mathrm{i}}$ \\
\hline Gemi Kabul Kapasitesi & 0,099 & 0,098 \\
Toplam Elleçleme Kapasitesi & 0,198 & 0,198 \\
Toplam Stoklama kapasitesi & 0,161 & 0,160 \\
Yükleme - Boşaltma ücreti & 0,301 & 0,301 \\
Ardiye ücreti & 0,243 & 0,243 \\
\hline
\end{tabular}

Kriterlerin ortalama $\left(\mathrm{M}_{\mathrm{i}}\right)$ ve normalleştirilmiş ağırlığ $\left(\mathrm{N}_{\mathrm{i}}\right)$ da hesaplanarak Tablo 5 ' de gösterilmiştir. Eşitlik $1-8$ yardımıyla kriterlerin birbirleri arasında değerlendirmelerinin yapılması sonucunda önem ağırlıkları elde edilmiştir. Elde edilen sonuçlar Şekil 1'de verilmiştir.

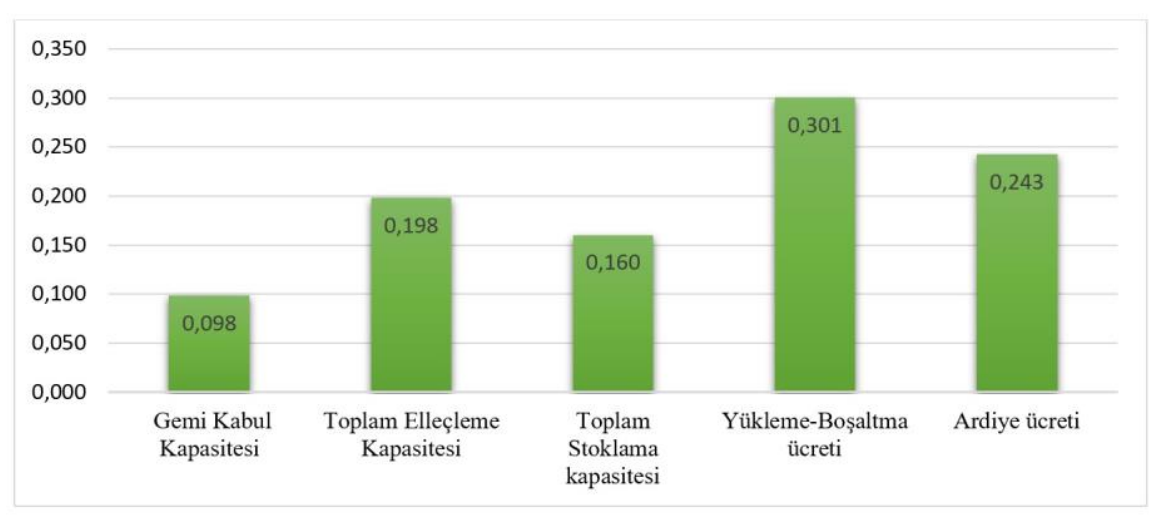

Şekil 1. Kriterlerin önem ağırlıkları

Kriterlerin önem ağırlıklarına bakıldığında, en yüksek değerin yükleme-boşaltma ücreti olduğu, bunu ardiye ücretinin ve limanın toplam elleçleme kapasitesinin takip ettiği sonucuna ulaşılmıştır. Yükleme-boşaltma ve ardiye ücreti kriterlerinin önem ağılıklarının yüksek olması firmaların maliyet kriterlerinin önemli olduğu, bunu yanı sıra limanın toplam elleçleme kapasitesinin yüksek olmasının da lojistik faaliyetlerin aksamaması adına kapasiteye verilen önemi göstermektedir.

\subsection{Alternatiflerin TOPSIS yöntemiyle belirlenmesi}

Alternatif olarak belirlenen Türkiye'de demiryolu bağlantısı olan 7 adet liman çok kriterli karar verme yöntemlerin TOPSIS yöntemi kullanılarak sıralanmıştır. Yöntemin kriterler ağırlıkları kısmında bulanık AHS yöntemi kullanılarak elde edilen ve Şekil 1'de verilen ağırlıklar kullanılmıştır. 
Tablo 6. Karar matrisinin oluşturulması

\begin{tabular}{|c|c|c|c|c|c|}
\hline Kriterler & $\begin{array}{c}\text { Gemi } \\
\text { Kabul } \\
\text { Kapasitesi }\end{array}$ & $\begin{array}{l}\text { Konteyner } \\
\text { Elleçleme } \\
\text { Kapasitesi }\end{array}$ & $\begin{array}{l}\text { Konteyner } \\
\text { depolama } \\
\text { kapasitesi }\end{array}$ & $\begin{array}{l}\text { Yükleme- } \\
\text { Boşaltma } \\
\text { ücreti }\end{array}$ & $\begin{array}{l}\text { Ardiye } \\
\text { ücreti }\end{array}$ \\
\hline Birim & (gemi/yıl) & $\begin{array}{c}(1000 \\
T E U / y l l)\end{array}$ & $(T E U / y \imath l)$ & kont/usd & gün/usd \\
\hline Haydarpaşa Limanı & 1.169 & 655.000 & 426.000 & 70,00 & 2 \\
\hline İzmir Liman & 2.767 & 1.164 .900 & 1.230 .807 & 70,00 & 3 \\
\hline Bandırma Limanı & 1.800 & 350.000 & 1.531 .175 & 100,00 & 5 \\
\hline Derince Limanı & 862 & 1.000 .000 & 2.500 .000 & 60,00 & 8 \\
\hline İskenderun Limanı & 770 & 1.000 .000 & 1.000 .000 & 100,00 & 8 \\
\hline Mersin Limanı & 4.200 & 2.600 .000 & 3.600 .000 & 105,00 & 5 \\
\hline Samsun Limanı & 1.130 & 250.000 & 3.650 .000 & 95,00 & 8 \\
\hline
\end{tabular}

7 adet liman için elde edilen veriler kullanılarak karar matrisi oluşturulmuş ve Tablo 6' da verilmiştir [28 - 33]. Sonrasında işlem kolaylığı için matris normalize edilmiş, bulanık AHS yöntemiyle elde edilen ve Şekil 1' de gösterilen kriter ağırlıkları kullanılarak da ağılıklı karar matrisi oluşturulmuştur. TOPSIS çözüm yönteminin devamı olarak ideal ve negatif ideal çözüm kümeleri oluşturulmuş, bu kümelerden ideal ve negatif ideal çözümlere yakınlıklar hesaplanmış ve son kısımda ise limanlar seçimi için elde edilen sıralama elde edilmiş ve Tablo 7' de verilmiştir.

Tablo 7. Liman seçimi öncelik sıralaması

\begin{tabular}{lll}
\hline Alternatifler & Öncelik değeri & Öncelik sırası \\
\hline Haydarpaşa Limanı & 0,1285 & 7 \\
İzmir Liman & 0,3120 & 6 \\
Bandırma Limanı & 0,3899 & 5 \\
Derince Limanı & 0,5078 & 2 \\
İskenderun Limanı & 0,4718 & 3 \\
Mersin Limanı & 0,8897 & 1 \\
Samsun Limanı & 0,4421 & 4 \\
\hline
\end{tabular}

\section{Sonuç ve Öneriler}

Türkiye'nin Modern İpek Yolunda orta koridorun merkezinde yer alması, kendisine büyük bir avantaj sağlamaktadır. Demir yolu ile gelecek malların transit şekilde Türkiye'den geçmesi, büyük potansiyelleri beraberinde getirmektedir. Orta koridor üzerinde efektif verim, kombine taşımacılık uygulamaları ile sağlanacaktır [34-35].

Bu çalışmada orta koridor üzerinden Türkiye'ye gelen ve diğer ülkelere deniz yolu ile devam edecek bir yük taşıması için ideal liman seçimi problemine çözüm getirilmiştir. Lojistik sektörü paydaşlarınca önem arz eden kriterler öncelikle bulanık AHS yöntemiyle ağırlıklandırılmış daha sonra demiryolu liman bağlantısı olan yedi adet liman bu kritelere ait veriler ile TOPSIS yöntemi kullanılarak sıralandırılmıştır. Elde edilen sonuçlar incelendiğinde, en ideal limanın diğerlerine göre üstünlük sağlayan bir sonuçla Mersin Limanı'nın olduğu gözlenmiştir. Mersin Limanı'nın özellikle elleçleme, ardiye ve gemi kabul kapasitesindeki üstünlüğü, önem arz eden iki kriter olan elleçleme ve ardiye ücretinde ise diğer limanlara göre yakın seviyede olması öne çıkmasında önemli etken olmuştur. 
Çalışma sonucunda Mersin Limanının önemi ortaya çıkmıştır. Akdeniz'in önemli limanlarından biri olan Mersin Limanı, Ortadoğu ülkelerinin transit merkezidir. İç Anadolu, Akdeniz ve Güneydoğu Anadolu bölgelerinin ithalat-ihracat kapısıdır. İlerleyen yıllarda Gaziantep-Mersin demir yolu ile önemi daha da artacaktır. Mersin limanı uzun vade de Orta koridor ile gelen yüklerin elleçleme merkezi olmaya yakındır.

\section{Kaynakça}

[1] Ö. Sacar, "İpek yolu güzergahında yapılan lojistik etkinliklerin günümüz lojistik faaliyetleri ile karşılaştırılması," Balıkesir Üniversitesi Sosyal Bilimler Enstitüsü, Balıkesir, 2018.

[2] Ç. Karataş and E. Z. Oral "Aktarma Limanlarının Seçim Kriterleri," 6. Ulusal Kıyı Mühendisliği Seтровуuти, pp. 149-156, 2005.

[3] E. Akbayırlı and E. Kurtuluş, "Container Port Selection in Contestable Hinterlands," Journal of ETA Maritime Science, vol. 5, no. 3, pp. 290-299, 2017.

[4] M. Pekkaya and U. Bucak, "Çok Kriterli Karar VermeYöntemleriyle Bölgesel Liman Kuruluş Yeri Seçimi: Batı Karadeniz'de Bir Uygulama," Uluslararası İktisadi ve İdari İncelemeler Derg., pp. 5-7, 2018.

[5] S. Z. Aydın, F. Bikitaş and İ. Balık, "Antalya Kruvaziyer Liman Projesinin Yer Seçim Kriterleri ve Sorumlu Turizm Açısından Değerlendirilmesi," Arch. Anesthesiol. Crit. Care, vol. 4, no. 4, pp. $527-$ $534,2018$.

[6] N. Özyağcı and E. Z. Oral, "Optimum Güzergâh Dikkate Alınarak Liman Kara Terminallerinin Yer seçimi: Örnek bir Çalışma Odessa," 7. Kıyı Mühendisliği Sempozyumu, pp. 645-655, 2011.

[7] H. Zeybek, "Demiryollarının Konteyner Limanı-Hinterlant Bağlantılarındaki Önemi: Mersin Limanı Örneği,” Demiryolu Mühendisliği, no.14, pp.49-64, 2021.

[8] H. Zeybek, "Yeni İpek Yolunun Kıtalar Arası Demiryolu Konteyner Taşımacıllı̆ına Etkisi: Pestle Analizi," Ömer Halisdemir Üniversitesi İktisadi ve İdari Bilimler Fakültesi Dergisi, vol.13, pp. 724740, 2020.

[9] A. Özel, "Çok kriterli karar verme yöntemlerinden vikor yöntemi ile konteyner liman yeri seçimi," Yaşar Üniversitesi, 2018.

[10] V. T. N. Nha, S. Djahel and J. Murphy, "A comparative study of vehicles' routing algorithms for route planning in smart cities," lst Int. Work. Veh. Traffic Manag. Smart Cities, 2012.

[11]M. B. Malchow and A. Kanafani, "A disaggregate analysis of port selection," Transp. Res. Part E Logist. Transp. Rev., vol. 40, pp. 317-337, 2004.

[12]P. R. Murphy and J. M. Daley, "Analysis Factors Selection of Port," American Society of Transportation and Logistics, vol. 34, no. 1, pp. 15-21, 2015.

[13]B. Slack, "Containerization, inter-port competition, and port selection," Maritime Policy \& Management,pp. 37-41, 2006.

[14] T. C. Lirn, H. A. Thanopoulou and A. K. C. Beresford, "Transhipment Port Selection and Decisionmaking Behaviour: Analysing the Taiwanese Case," Int. J. Logist. Res. Appl., vol.6, no 4, pp.229-244, 2003.

[15]L. G. Alonso and J. Sanchez-Soriano, "Port selection from a hinterland perspective," Marit. Econ. Logist., vol. 11, no. 3, pp. 260-269, 2009.

[16] T. C. Lirn, H. A. Thanopoulou, M. J. Beynon and A. K. C. Beresford, "An application of AHP on transhipment port selection: A global perspective," Marit. Econ. Logist., vol.6, no.1, pp.70-91, 2004.

[17] J. S. L. Lam and J. Dai, “A decision support system for port selection," Transp. Plan. Technol., vol. 35, no. 4, pp. 509-524, 2012.

[18]L. Feng, L. Liu and H. Zhang, "Game Theory-Based Pathway Selection for Fair and Reciprocal Cooperation among Ports along the Maritime Silk Road," Math. Probl. Eng., vol. 2019.

[19] C. Song, Z.Xu, Y. Zhang and X. Wang, "Dynamic hesitant fuzzy Bayesian network and its application in the optimal investment port decision making problem of twenty-first century maritime silk road," Appl Intell 50, 1846-1858,2020.

[20]T. Gao, S. Na, X. Dang and Y. Zhang, "Study of the competitiveness of Quanzhou Port on the Belt and Road in China based on a fuzzy-AHP and ELECTRE III model," Sustain., vol. 10, no. 4, 2018.

[21]C. Chou, "A fuzzy MCDM method for solving marine transshipment container port selection problems," Appl. Math. Comput., vol. 186, no. 1, pp. 435-444, 2007.

[22] N. K. Tran, "Studying port selection on liner routes: An approach from logistics perspective," Res. 
Transp. Econ., vol. 32, no. 1, pp. 39-53, 2011.

[23] V. Bagočius, K. E. Zavadskas and Z. Turskis, "Multi-criteria selection of a deep-water port in Klaipeda," Procedia Eng., vol. 57, pp. 144-148, 2013.

[24]D. E. Onwuegbuchunam, "Port selection criteria by shippers in Nigeria: A discrete choice analysis," Int. J. Shipp. Transp. Logist., vol. 5, no. 4-5, pp. 532-550, 2013.

[25]E.K. Zavadskas, Z. Turskıs and J. Antucheviciene, "Selecting a Contractor by Using a Novel Method for Multiple Attribute Analysis: Weighted Aggregated Sum Product Assessment with Grey Values (WASPAS-G)", Studies in Informatics and Control, 24 (2): 141-150, 2015.

[26] T. Demirel, N. Ç. Demirel, and C. Kahraman, "Fuzzy analytic hierarchy process and its application," Springer Optim. Its Appl., vol. 16, no. June 2014, pp. 53-83, 2008.

[27]C. L. Hwang and K. Yoon, "Multiple Attribute Decision Making: Methods and Applications," Springer-Verlag, 1981.

[28]TCDD, [Online]. Available: https://www.tcdd.gov.tr/kurumsal/limanlar, [Accessed September 1, 2021].

[29] Port of Bandırma, [Online]. Available: http://www.portofbandirma.com.tr/kurumsal/hakkimizda, [Accessed September 1, 2021].

[30] Safi Port, [Online]. Available: https://www.safiport.com.tr/tarihce, [Accessed September 1, 2021].

[31]Limak Ports, [Online]. Available: http://www.limakports.com.tr/tr/limakports/tarihce, [Accessed September 1, 2021].

[32] Mersin International Port, [Online]. Available: https://www.mersinport.com.tr/hakkimizda/detay/ Hakkimizda/13/1/0, [Accessed September 1, 2021].

[33] Samsun Port, [Online]. Available: https://www.samsunport.com.tr/tr/kurumsal/tanitim-ve-tarihce, [Accessed September 1, 2021].

[34] S. Özdemir, Ö. Sacar, E. Özcan, "Dijkstra algoritması kullanılarak ipek yolu koridorları arasında en kısa ulaştırma güzergâhının belirlenmesi," Demiryolu Mühendisliği, no. 13, pp. 97-105, 2021.

[35] S. Özdemir, B. Keskin, T. Eren and E. Özcan, "Türkiye'deki lojistik merkezleri yatırım önceliklerinin değerlendirilmesinde çok kriterli karar modeli önerisi,” Demiryolu Mühendisliği, no. 12, pp. 83-94, 2020 .
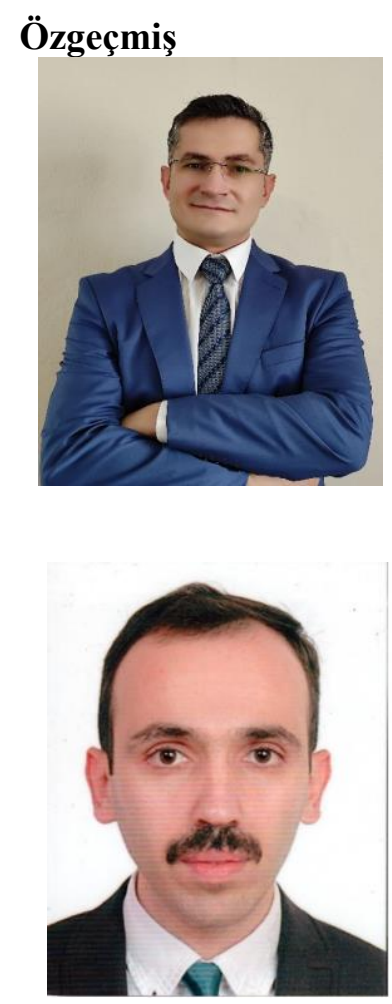

\section{Ömer SACAR}

1986 y1lında Bursa'da doğdu. 2009'da İstanbul Üniversitesi Ulaştırma ve Lojistik Fakültesi'nden mezun oldu. 2018'de Balıkesir Üniversitesi İşletme yüksek lisans eğitimini tamamladı. 2010 senesinden Türkiye'nin ilk lojistik öğretmenlerinden biri olarak MEB'de göreve başlayan SACAR, 2021'den itibaren Bursa Osmangazi Ergin Ağaç MTAL'de göreve devam etmektedir. Lojistik alanında yüzlerce öğrenci ve eğitimciye yönelik Avrupa projeleri yazmakta ve yönetmektedir.

E-Posta: omersacar@hotmail.com

\section{Sezgin ÖZDEMIR}

1987 yılında Bartın'da doğdu. 2004 yılında Karabük Mustafa Yazıcı Lisesi'nden mezun oldu. 2010 y1lında İstanbul Üniversitesi Ulaştırma ve Lojistik, 2016 yılında Hoca Ahmet Yesevi Üniversitesi Endüstri Mühendisliği bölümlerinde lisans eğitimlerini tamamladı. Yüksek lisans eğitimini Kırıkkale Üniversitesi Endüstri Mühendisliği bölümünde almış olup TCDD Taşımacılık A.Ş.' de Yüksek Mühendis olarak çalışmaktadır.

E-Posta: ozdemir_sezgin@hotmail.com

\section{Beyanlar:}

Bu makalede bilimsel araştırma ve yayın etiğine uyulmuştur. Yazarların katkıları: Yazar katkıları belirtilmemiştir. 